University of Nebraska - Lincoln

DigitalCommons@University of Nebraska - Lincoln

9-2009

\title{
Investigation of Endocannabinoid Modulation of Conditioned Responding Evoked by a Nicotine CS and The Pavlovian Stimulus Effects of CP 55,940 in Adult Male Rats
}

\author{
Jennifer E. Murray \\ University of Nebraska-Lincoln, jem98@cam.ac.uk \\ Nicole R. Wells \\ University of Nebraska-Lincoln \\ George D. Lyford \\ University of Nebraska-Lincoln \\ Rick A. Bevins \\ University of Nebraska-Lincoln, rbevins1@unl.edu
}

Follow this and additional works at: https://digitalcommons.unl.edu/psychfacpub

Part of the Psychiatry and Psychology Commons

Murray, Jennifer E.; Wells, Nicole R.; Lyford, George D.; and Bevins, Rick A., "Investigation of Endocannabinoid Modulation of Conditioned Responding Evoked by a Nicotine CS and The Pavlovian Stimulus Effects of CP 55,940 in Adult Male Rats" (2009). Faculty Publications, Department of Psychology. 384.

https://digitalcommons.unl.edu/psychfacpub/384

This Article is brought to you for free and open access by the Psychology, Department of at DigitalCommons@University of Nebraska - Lincoln. It has been accepted for inclusion in Faculty Publications, Department of Psychology by an authorized administrator of DigitalCommons@University of Nebraska - Lincoln. 


\title{
Investigation of endocannabinoid modulation of conditioned responding evoked by a nicotine CS and the Pavlovian stimulus effects of CP 55,940 in adult male rats
}

\author{
Jennifer E. Murray, Nicole R. Wells, George D. Lyford, and Rick A. Bevins
}

Department of Psychology, University of Nebraska - Lincoln, Lincoln, NE 68588-0308, USA

Corresponding author - R. A. Bevins, email rbevins1@unl.edu

\begin{abstract}
Rationale - The cannabinoid $\mathrm{CB}_{1}$ receptor antagonist/inverse agonist rimonabant (SR 141716) has been shown to block reinforcing and rewarding effects of nicotine. Research has not investigated whether the cannabinoid system is involved in the interoceptive stimulus effects of nicotine functioning as a conditional stimulus (CS).

Objective - We examined the effects of rimonabant and the $\mathrm{CB}_{1 / 2}$ receptor agonist, $\mathrm{CP} 55,940$, on responding evoked by a nicotine CS in rats. Additionally, we determined whether CP 55,940 functioned as a CS or a Pavlovian positive drug feature

Materials and methods - Pavlovian discrimination training involved intermixed nicotine $(0.2 \mathrm{mg}$ base $/ \mathrm{kg})$ and saline sessions with intermittent access to water only on nicotine. Antagonism tests with rimonabant $(0.1-3 \mathrm{mg} / \mathrm{kg})$ and substitution tests with CP 55,940 (0.003-0.1 mg/ kg) followed. An effective dose of CP 55,940 was tested against the nicotine generalization curve. A separate group received CS training with CP 55,940 (0.01 mg/ kg). Two other groups were trained using CP 55,940 (0.01 or $0.03 \mathrm{mg} / \mathrm{kg})$ as a positive drug feature in which a brief light CS signaled access to water only on CP 55,940 sessions

Results - Rimonabant blocked nicotine-evoked responding. CP 55,940 partially substituted for nicotine and enhanced responding to lower nicotine doses. Overall, CP 55,940 did not acquire control of conditioned responding in either Pavlovian drug discrimination task

Conclusions - The cannabinoid system was involved in the CS effects of nicotine. This finding is counter to the operant drug discrimination research with nicotine as a discriminative stimulus, warranting further research into this possible dissociation.
\end{abstract}

Keywords: appetitive conditioning, associative learning, cannabinoid receptor, nicotinic acetylcholine, occasion setting, smoking cessation

\section{Introduction}

Recent attention has been given to cannabinoid compounds for use in smoking cessation. Of particular interest have been compounds related to the cannabinoid $\mathrm{CB}_{1}$ receptor antagonist/inverse agonist rimonabant, or SR 141716. Cannabinoid antagonists have appeared promising for use as smoking pharmacotherapies, and several pharmaceutical companies have worked to develop a marketable compound. For example, another $\mathrm{CB}_{1}$ antagonist, surinabant (SR 147778; Lamota et al. 2008; Rinaldi-Carmona et al. 2004) completed Phase II clinical trials in Europe in 2008 before development was discontinued because of adverse side effects.

Preclinical findings in rodents describing the role of cannabinoid activation on behavioral effects of nicotine have been reviewed elsewhere (e.g., Beardsley and Thomas 2005; Castañé et al. 2005). Briefly, rimonabant has been found to decrease nicotine self-administration (Cohen et al. 2002; Kodas et al. 2007), cue-induced reinstatement of nicotine seeking (Cohen et al. 2004; De Vries et al. 2005), and nicotine-conditioned place preferences (Forget et al. 2005; Le Foll and Goldberg 2004). The operant discriminative stimulus $\left(S^{D}\right)$ effects of nicotine do not appear to be affected by pretreatment with rimonabant (Cohen et al. 2002; Le Foll and Goldberg 2004; Zaniewska et al. 2006). 
These cannabinoid effects on nicotine led us to examine the potential role for cannabinoid activation in the expression of the conditional stimulus (CS) effects of nicotine in an appetitive Pavlovian conditioning task (cf. Besheer et al. 2004). In this task, rats receive a subcutaneous (SC) injection of nicotine or saline before placement in a conditioning chamber. On nicotine sessions, liquid sucrose (i.e., the unconditioned stimulus; US) is delivered intermittently. Sucrose is not available on intermixed saline sessions. Using head entries into the sucrose receptacle before the first sucrose delivery as a measure of the conditioned response (i.e., CR; goal tracking; Farwell and Ayres 1979), nicotine serves as an interoceptive CS as evidenced by increased dipper entries on nicotine compared to saline sessions. The most notable procedural distinction between this task and the operant drug discrimination models is that there is no explicit response requirement for reinforcement to be delivered in the discriminated goal-tracking task. Although a rat must insert its head into the dipper to access the sucrose, the delivery of the sucrose is determined by the experimenter - not the rat. Recent research suggests that the CS effects of nicotine might involve somewhat different neuropharmacological processes than that of a $S^{D}$. Specifically, $N$-methyl-D-aspartate receptor blockade attenuated conditioned responding evoked by a nicotine CS (Murray and Bevins 2007a), but has not been shown to affect operant responding controlled by $S^{\mathrm{D}}$ effects of nicotine (Kim and Brioni 1995; Zakharova et al. 2005).Therefore, we examined the effects of the cannabinoid $\mathrm{CB}_{1}$ receptor antagonist/inverse agonist, rimonabant (Pan et al. 1998; Rinaldi-Carmona et al. 1994) and the non-selective cannabinoid $\mathrm{CB}_{1 / 2}$ receptor agonist, CP 55,940 (Little et al. 1988; Thomas et al. 1998) on nicotine-evoked conditioned responding. We also examined whether CP 55,940 served as a CS or as a Pavlovian drug feature.

\section{Materials and methods}

Subjects For all experiments, we used male SpragueDawley rats (314 $\pm 10 \mathrm{~g}$ at start of study) from Harlan (Indianapolis, IN, USA) that were previously used in brief cocaine/novelty place conditioning experiments (Reichel and Bevins 2008; unpublished research). Rats were taken from control and low-dose cocaine groups; care was taken to match histories as much as possible across the different conditions of the present report. Before the start of the present studies, rats were handled for at least $3 \mathrm{~min} /$ day for 3 days. They were housed individually in clear $48.3 \times 26.7 \times 20.3 \mathrm{~cm}(l \times w \times h)$ polycarbonate cages lined with wood shavings in a temperature- and humidity-controlled colony. Food was continuously available in the home cage. Rats were 23$\mathrm{h}$ water-restricted; access to water for the hour occurred after each daily session. All sessions were conducted during the light portion of a 12-h light:dark cycle with lights on at $0600 \mathrm{~h}$. Protocols were approved by the University of Nebraska-Lincoln Animal Care and Use Committee and followed the "Guidelines for the Care and Use of Mammals in Neuroscience and Behavioral Research" (National Research Council 2003).

Apparatus Eight conditioning chambers (ENV-008CT; Med Associates, Inc., St. Albans, VT, USA) measuring $30.5 \times 24.1 \times 21.0 \mathrm{~cm}(l \times w \times h)$ were used. Sidewalls were aluminum; the ceiling and front and back walls were clear polycarbonate. Each chamber was equipped with a recessed receptacle $(5.2 \times 5.2 \times 3.8 \mathrm{~cm} ; l \times w \times d)$ on one sidewall. A dipper arm raised a $0.1-\mathrm{ml}$ cup of distilled water into the receptacle. Water, rather than sucrose, served as the US because cannabinoid compounds can affect caloric consumption (e.g., Glick and Milloy 1972; Xie et al. 2007). An infrared emitter/detector unit, $1.2 \mathrm{~cm}$ into the receptacle and $3 \mathrm{~cm}$ above the chamber floor, monitored head entries into the dipper. A second infrared emitter/detector unit, $4 \mathrm{~cm}$ above the rod floor, bisected the chamber $14.5 \mathrm{~cm}$ from the sidewall containing the receptacle. This unit provided a measure of locomotor activity in the chamber. Two white stimulus lights ( $2.54 \mathrm{~cm}$ diameter; $28 \mathrm{~V}, 100 \mathrm{~mA}$ ) were each mounted on the sidewall on either side of the dipper receptacle, $14.6 \mathrm{~cm}$ above the metal rod floor and $3.5 \mathrm{~cm}$ from either the front or the back wall. Illumination of the lights served as the discrete CS in the CP 55,940 positive feature experiments. Each chamber was enclosed in a light- and sound-attenuating cubicle fitted with a fan to provide airflow and mask noise. A personal computer with Med Associates interface and software (Med-PC for Windows, version IV) controlled water deliveries and recorded dipper entries and locomotor activity.

Drugs (-)-Nicotine hydrogen tartrate (Sigma, St. Louis, MO, USA), rimonabant (RTI International, Research Triangle Park, NC, USA), and CP 55,940 (RTI International) were used. Nicotine was mixed in saline then adjusted to a $\mathrm{pH}$ of $7.0 \pm 0.2$. Rimonabant and CP 55,940 were mixed in a 1:1:18 Tween-80: 100\% ethanol: distilled water vehicle. Nicotine was injected subcutaneously (SC) at $1 \mathrm{ml} / \mathrm{kg}$ with a 5-min injection-to-placement interval (IPI). Rimonabant and CP 55,940 were injected intraperitoneally (IP). Rimonabant was given at $2 \mathrm{ml} / \mathrm{kg}$ with a 40 min IPI (cf. Wiley et al. 1995a); CP 55,940 was given at a volume of $1 \mathrm{ml} / \mathrm{kg}$ with a $30 \mathrm{~min}$ IPI (cf. De Vry and Jentzsch 2003; Mauler et al. 2002). Nicotine doses are reported in base form.

Nicotine CS training and testing Rats $(n=16)$ were given an injection of $0.2 \mathrm{mg} / \mathrm{kg}$ nicotine each day for 3 days in the home cage to attenuate the initial locomotor suppressant effects of nicotine (cf. Murray and Bevins 2007a). 
Daily training sessions began the day after the last nicotine injection. Rats received either $0.2 \mathrm{mg} / \mathrm{kg}$ nicotine or saline before the start of each 20-min session. During nicotine sessions, there were 36 deliveries of $4 \mathrm{~s}$ access to water. Four different programs that varied when water was delivered were created to discourage timing of water deliveries. The average time before the first water delivery across programs was $137 \mathrm{~s}$ with a range of 124-152 s. No water was delivered during saline sessions, but there were 4-s "empty" intervals to maintain consistency between nicotine and saline sessions. Session types and programs were randomly assigned with the restriction that no more than two nicotine or two saline sessions occurred in a row. Training continued for 28 sessions. Following acquisition of the discrimination, rats entered testing. On the first four consecutive days of each 5-day cycle, rats received two nicotine and two saline training sessions as described previously. If the discrimination criterion was met (see later), a 4-min test session occurred in place of a training session on day 5; water was withheld in testing. If the criterion was not met, the rat remained in its home cage on that day. Nicotine generalization was tested first, followed by tests of rimonabant antagonism then CP 55,940 substitution. Finally, nicotine generalization was conducted again concurrently with CP 55,940 pretreatment of the nicotine dose-effect curve. Within each phase, the test doses were randomly intermixed for each rat. All ligands and doses in a phase were completed before beginning the next phase.

CP 55,940 CS training A separate set of rats $(n=16)$ re-

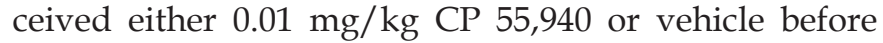
each 20-min session. Water was delivered only in the $\mathrm{CP}$ 55,940 sessions. The programs and their order were the same as the nicotine CS experiment. Following 56 sessions of training with the CP 55,940 CS, rats were randomly assigned to one of two groups. One group remained with CP 55,940 training as described for another eight CP 55,940 and eight vehicle sessions. The other group was switched from CP 55,940 training to $0.2 \mathrm{mg} /$ $\mathrm{kg}$ nicotine training for eight nicotine and eight saline sessions.

CP 55,940 feature-positive training Rats $(0.01 / 0.03 \mathrm{mg} /$ $\mathrm{kg}$ group, $n=14 ; 0.03 \mathrm{mg} / \mathrm{kg}$ group, $n=6$ ) received dipper training consisting of three 50-min sessions. Each daily session was initiated with the rat's first head entry into the receptacle. The probability of receiving $4 \mathrm{~s}$ access to water decreased from 0.267 to 0.05 per $60 \mathrm{~s}$ over the three sessions. Acquisition training began the day after the last dipper training session. Rats were injected with CP 55,940 or vehicle 30-min before chamber placement. During each 20-min session, there were eight 15-s light CS presentations. On CP 55,940 sessions, each offset of the light was followed immediately by 4 -s access to water. Four different programs were used to vary the timing of light presentations and water delivery. The average time to the first light onset was $135 \mathrm{~s}$ (range of 90-180 s) with a mean intertrial interval of $120 \mathrm{~s}$ (range of 74-165 s). On vehicle sessions, light presentations were matched with those of CP 55,940 sessions and 4-s "empty" intervals occurred in place of water deliveries to ensure identical session length. CP 55,940 and vehicle sessions were intermixed randomly with the restrictions that no more than two of a session type occurred in a row. The $0.01 / 0.03 \mathrm{mg} / \mathrm{kg}$ group received 60 training sessions at $0.01 \mathrm{mg} / \mathrm{kg}$ followed by 60 training sessions at $0.03 \mathrm{mg} / \mathrm{kg}$ CP 55,940; the $0.03 \mathrm{mg} / \mathrm{kg}$ group received 120 training sessions.

Dependent measures In the CS experiments, the primary dependent measure was rate of dipper entries per second before the first water delivery. To allow for comparable measurement between drug (i.e., water) and vehicle (i.e., no water) sessions, the program types were matched for timing of the intervals from which the dipper entry rate was taken. The dependent measure for test sessions was the dipper entry rate in the first $2 \mathrm{~min}$ of the test. To qualify to test, dipper entry rate on each nicotine session was a minimum of 0.01 entries per second higher than each saline session within that testing cycle. Rate of locomotor activity in the chamber (beam breaks per second during the same interval as used for dipper entries) was also analyzed. In feature-positive experiments, the primary dependent measure was the initial elevation score of a session. This score was calculated as the number of dipper entries recorded during the first 15-s presentation of the light CS minus the number of dipper entries recorded during the 15-s interval before the light (CS period-pre-CS period). A positive value indicates more dipper entries during the CS. Locomotor activity was also recorded throughout the session.

Data analyses For acquisition, two-way repeated measures analyses of variance (ANOVAs) were conducted with Drug (nicotine versus saline or CP 55,940 versus vehicle) as one factor and Session as the other factor for the dipper entry and activity measures. Generalization, antagonism, and substitution tests were analyzed with one-way repeated measures ANOVAs with Drug Dose as the factor. Finally, the regeneration of the nicotine generalization curves with CP 55,940 pretreatment were examined with a two-way repeated measures ANOVA using Drug (CP 55,940 or none) as one factor and Nicotine Dose as the other factor. Significant effects in substitution and antagonism ANOVAs were followed with Tukey's honestly significant difference (HSD) tests. Significant interactions in the two-way acquisition ANOVAs prompted selective use of paired $t$ tests with Bonferroni's correction to compare drug conditions within 
each session. Median effective doses $\left[\mathrm{ED}_{50} \mathrm{~s}\right.$ (95\% confidence intervals)] were calculated using the least squares linear regressions on nicotine generalization curves and testing that resulted in full blockade of the CS effects of nicotine. Statistical significance was declared when $p<$ 0.05 for all tests. Only significant values are reported.

\section{Results}

Nicotine CS training and testing As shown in Figure 1a, the discrimination was acquired by the eighth day of training. This impression was supported by a significant
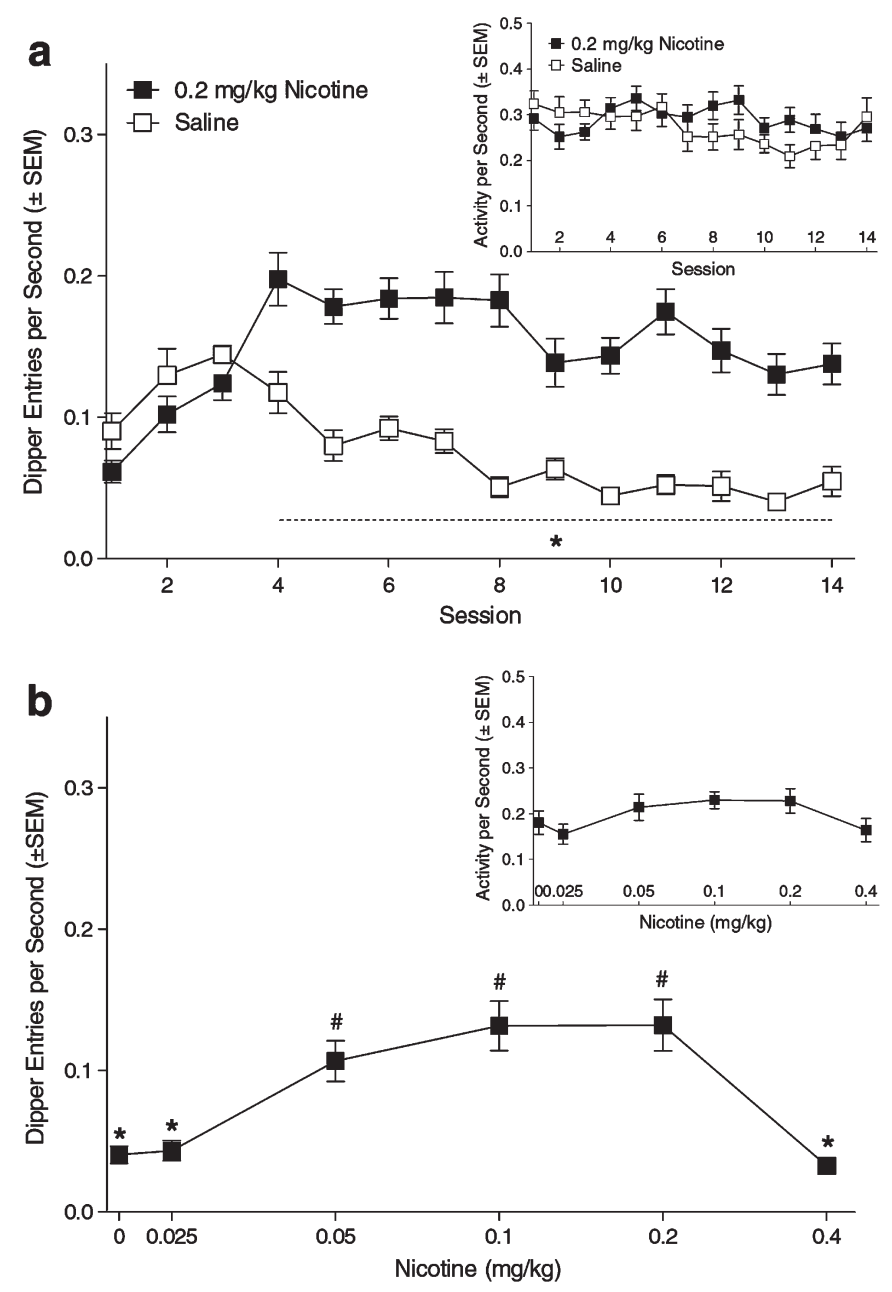

Figure 1. Panel a shows dipper entries per second before the first water delivery on nicotine sessions compared to equivalent time on saline sessions. ${ }^{*}$ denotes significant difference between nicotine and saline sessions. The inset graph of panel a shows locomotor activity per second. Panel $\mathbf{b}$ shows dipper entries per second during nicotine generalization tests. *denotes significant difference from the $0.2 \mathrm{mg} / \mathrm{kg}$ nicotine training dose. \# denotes significant difference from saline $(0 \mathrm{mg} / \mathrm{kg}$ nicotine) responding. The inset graph of panel $\mathbf{b}$ shows the locomotor activity per second during generalization tests
Drug $\times$ Session interaction, $F(13,195)=13.03, p<.001$, followed by paired $t$ tests with Bonferroni's correction indicating that for sessions 4-14, dipper entries were higher on nicotine than saline sessions, ts $(15) \geq 4.38$, ps $<0.001$. Overall higher response levels on nicotine compared to saline was also supported by a main effect of Drug, $F(1,15)=100.49, p<0.001$. Although inspection of the inset graph does not suggest a systematic effect of nicotine on locomotor activity, there was a Drug $\times$ Session interaction, $F(13,195)=1.84, p<.05$. However, none of the post-hoc comparisons were significant.

As shown in Figure 1b, conditioned responding diminished as the test dose of nicotine decreased from the training dose $(0.2 \mathrm{mg} / \mathrm{kg})$ to saline $\left[\mathrm{ED}_{50}=0.052(0.03-\right.$ $0.074) \mathrm{mg} / \mathrm{kg}$. There was a main effect of Drug Dose, $F(5,75)=17.93, p<0.001$. Follow-up Tukey's HSD tests found that $0.05,0.1$, and $0.2 \mathrm{mg} / \mathrm{kg}$ nicotine evoked greater responding than saline, and that $0,0.025$, and 0.4 $\mathrm{mg} / \mathrm{kg}$ evoked lower responding than the $0.2 \mathrm{mg} / \mathrm{kg}$ training dose of nicotine, $\mathrm{HSD}_{\mathrm{mmd}}=0.046$. There was no significant change in locomotor activity (inset graph) as a function of nicotine dose.

Results from antagonism and substitution testing are shown in Figure 2. During these phases, two rats were removed from the study for failure to maintain the discrimination $(n=14)$. Pretreatment with increasing doses of rimonabant decreased the nicotine-evoked CR (Figure 2a). The main effect of Drug Dose, $F(4,52)=17.87$, $p<0.001$, showed 1 and $3 \mathrm{mg} / \mathrm{kg}$ rimonabant decreased nicotine-evoked responding compared to saline pretreatment, $\mathrm{HSD}_{\mathrm{mmd}}=0.045\left[\mathrm{ED}_{50}=1.09(0.49-1.69) \mathrm{mg} /\right.$ $\mathrm{kg}$ ]. Of those two doses, $1 \mathrm{mg} / \mathrm{kg}$ was also different from the vehicle baseline. Relative to vehicle pretreatment, the highest dose of rimonabant reduced nicotineinduced locomotor activity (inset graph), $F(4,52)=4.15$, $p<0.01$, to a level comparable to vehicle only, $\mathrm{HSD}_{\mathrm{mmd}}$ $=0.078$ (i.e., no nicotine).

There was an inverted U-shaped pattern of $\mathrm{CP}$ 55,940 substitution for the nicotine CS (Figure 2b). There was a main effect of Drug Dose, $F(4,52)=6.77$, $p<0.001$. Conditioned responding on $0.01 \mathrm{mg} / \mathrm{kg} \mathrm{CP}$ 55,940 was significantly higher than vehicle alone, HS$\mathrm{D}_{\mathrm{mmd}}=0.028$. This dose also differed from the $0.2 \mathrm{mg} /$ $\mathrm{kg}$ nicotine baseline. The $0.1 \mathrm{mg} / \mathrm{kg}$ dose of CP 55,940 reduced locomotor activity relative to vehicle alone and nicotine (inset graph), $F(4,52)=6.61, p<0.001$, HS$\mathrm{D}_{\mathrm{mmd}}=0.06$.

The dose of CP 55,940 that partially substituted for the nicotine CS $(0.01 \mathrm{mg} / \mathrm{kg})$ was assessed to determine if it could shift the nicotine dose-effect curve. During this phase, one more rat was removed for poor discrimination performance $(n=13)$. As shown in Figure 2c, CP 55,940 appeared to enhance nicotine-appropriate responding. There was a main effect of Drug, $F(1$, $12)=7.07, p<.001$, and a Drug $\times$ Nicotine Dose interaction, $F(3,36)=2.88, p<.05$. CP 55,940 enhanced re- 
sponding to saline and to $0.1 \mathrm{mg} / \mathrm{kg}$ nicotine, $\mathrm{HSD}_{\mathrm{mmd}}$ $=0.038\left[\mathrm{ED}_{50} \mathrm{~s}=0.043(0.025-0.06) \mathrm{mg} / \mathrm{kg}\right.$ for nicotine alone; $0.049(0.022-0.075) \mathrm{mg} / \mathrm{kg}$ for CP 55,940 pretreatment]. Although CP 55,940 showed partial substitution for the training dose of nicotine twice and enhanced responding to a low dose of nicotine, these effects did not translate into a shift in the $\mathrm{ED}_{50}$ for nicotine. A Type I error seems unlikely given the replication of partial substitution. The outcome may instead be a product of not having enough test doses along the linear portion of the dose-effect curves. Locomotor activity appeared relatively stable across nicotine doses (inset graph). However, there was a significant Drug $\times$ Nicotine Dose interaction, $F(3,36)=5.39, p<0.01$; post-hoc comparisons found no differences $\mathrm{HSD}_{\mathrm{mmd}}=0.069$.

CP 55,940 CS training When CP 55,940 was trained as the CS, the discrimination was not acquired even when training continued for twice as long as the nicotine CS (Figure 3a). There was a significant Drug $\times$ Session interaction, $F(27,405)=1.90, p<0.01$. However, none of the comparisons were significant following Bonferroni's correction tests. Activity (Figure 3c) was similar regardless of drug treatment.

For rats that remained on CP 55,940 CS training, CP 55,940 evoked slightly higher levels of dipper entries than vehicle (Figure $3 \mathrm{~b}$, top panel) as shown by a main effect of Drug, $F(1,7)=5.87, p<0.05$. Although this result suggests potential CS effects of CP 55,940, the discrimination was weak and not maintained throughout training. There were no differences in activity for this subset of rats (Figure 3d, top panel). In contrast, rats switched to nicotine quickly acquired the discrimination (Figure $3 \mathrm{~b}$, bottom panel). There was a significant Drug $\times$ Session interaction, $F(7,49)=14.74, p<0.001$. There was more responding on nicotine than saline for sessions 31 and 33-36, ts $(7) \geq 3.88, p s<0.0063$. For activity (Figure 3d, bottom panel), there was a significant Drug $\times$ Session interaction, $F(7,49)=2.25, p<0.05$. Nicotine decreased activity on session $30, t(7)=4.20, p<0.0063$.

CP 55,940 feature positive training: $0.01 / 0.03 \mathrm{mg} / \mathrm{kg}$ group The light CS came to evoke a goal-tracking CR (Figure 4a). The main effect of Session supports the observation that dipper entries during the light presentations steadily increased, $F(29,377)=4.48, p<0.001$. However, rats did not discriminate between $0.01 \mathrm{mg} / \mathrm{kg} \mathrm{CP} \mathrm{55,940}$ sessions (water reinforced) and the vehicle sessions (non-reinforced). There was no main effect of Drug or Drug $\times$ Session interaction. After switching from 0.01 $\mathrm{mg} / \mathrm{kg}$ to $0.03 \mathrm{mg} / \mathrm{kg}$ CP 55,940 , weak discrimination performance emerged [main effect of Drug, $F(1,13)=$ $18.13, p<.001]$. Response rates were stable across trials resulting in no main effect of Session or Drug $\times$ Session interaction. CP 55,940 evoked higher locomotor activity than vehicle at both training doses (Figure $4 b$ ). For
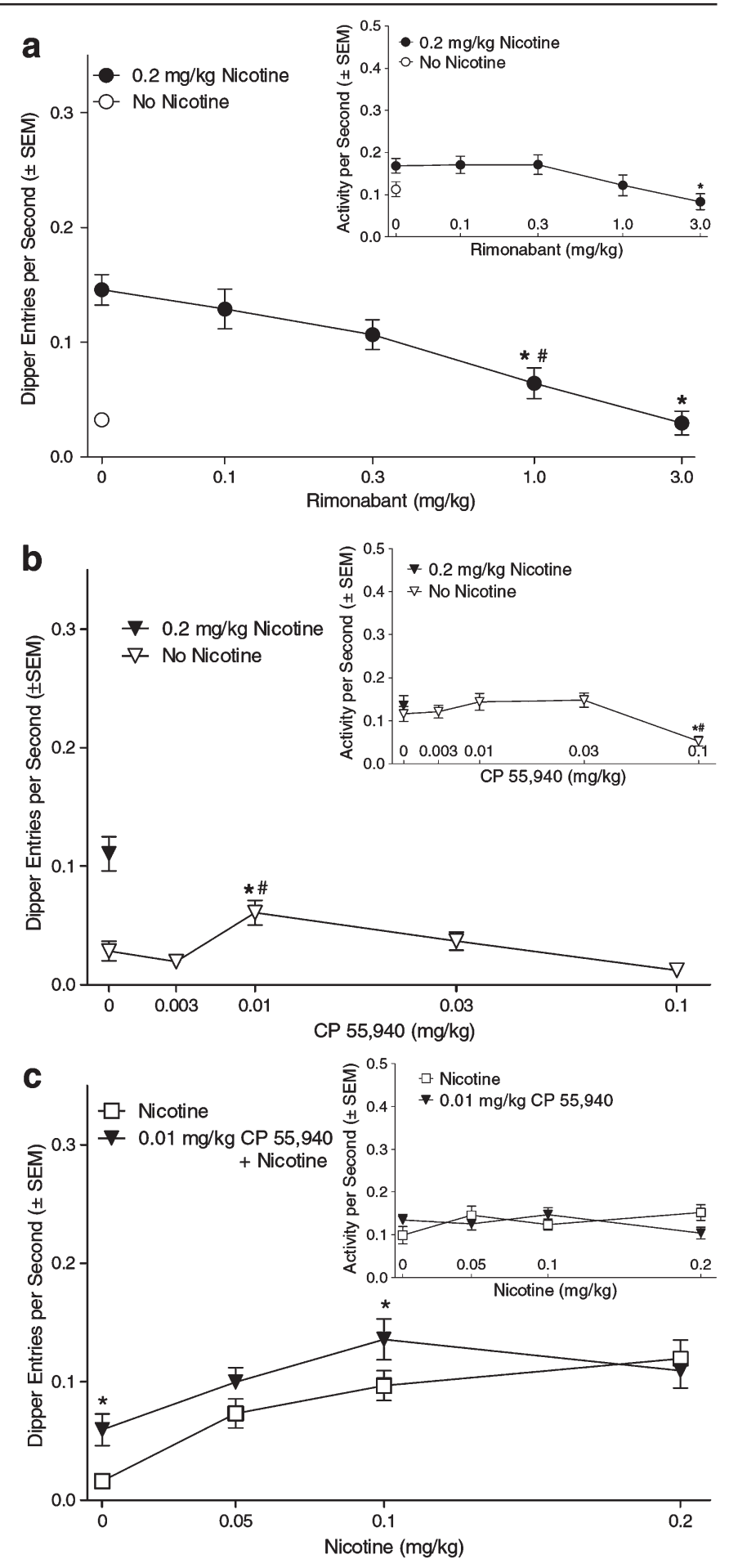

Figure 2. Panels a and $\mathbf{b}$ show dipper entries per second during rimonabant and CP 55,940 tests, respectively. Inset graphs for each panel show locomotor activity per second during the tests. *denotes significant difference from vehicle condition of the given drug test. \# denotes a further significant difference from the control baseline (no nicotine for rimonabant and 0.2 $\mathrm{mg} / \mathrm{kg}$ nicotine for CP 55,940). Panel c shows dipper entries per second for pretreatment of a range of nicotine doses with $0.01 \mathrm{mg} / \mathrm{kg} \mathrm{CP} \mathrm{55,940.} \mathrm{*denotes} \mathrm{significant} \mathrm{difference} \mathrm{from} \mathrm{the}$ same dose of nicotine with no pretreatment. The inset graph shows locomotor activity per second 

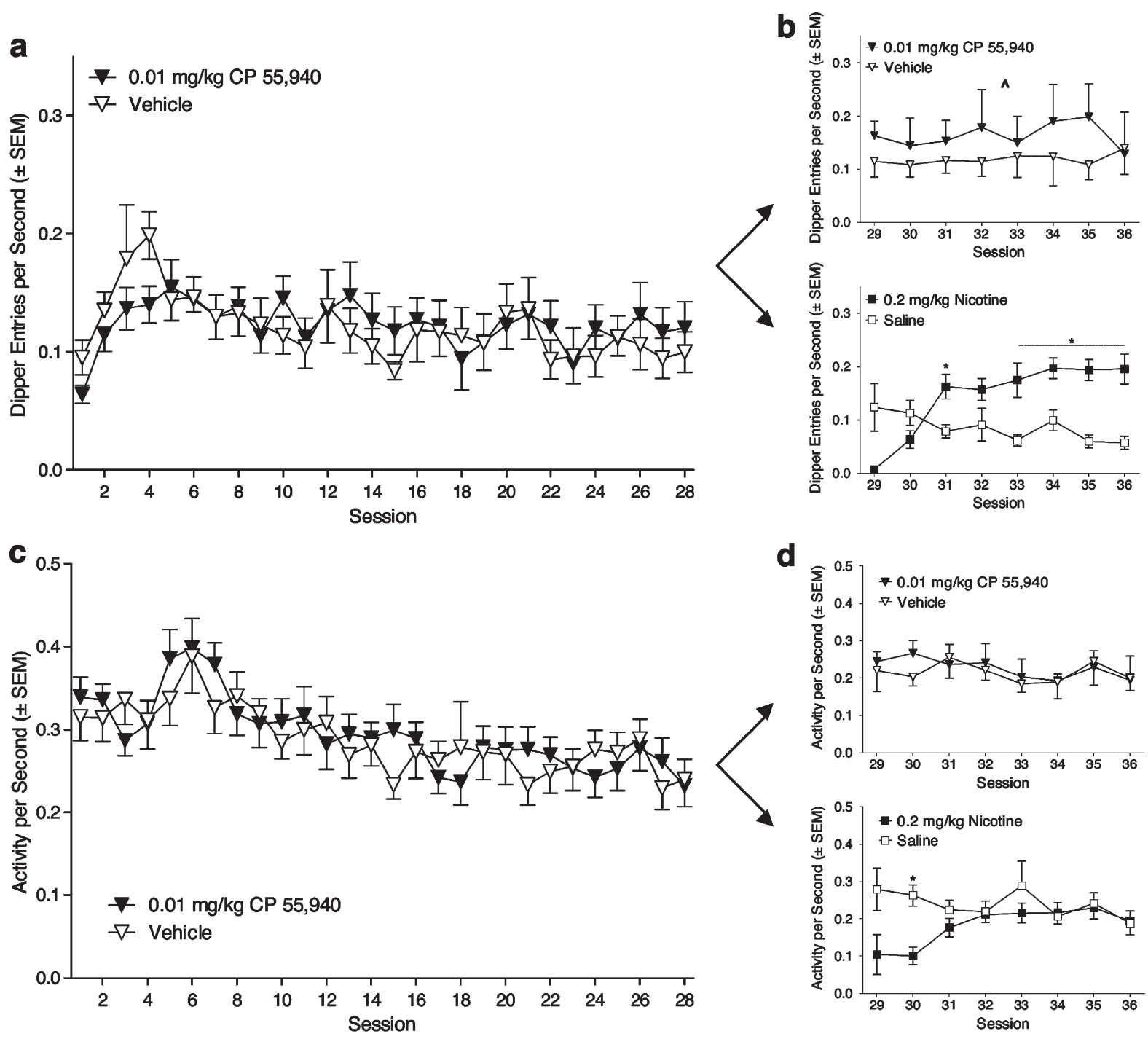

Figure 3. Panel a shows dipper entries per second during $0.01 \mathrm{mg} / \mathrm{kg}$ CP 55,940 CS training. Panel b shows dipper entries per second for rats remaining on CP 55,940 training (top graph) and switched from CP 55,940 CS to nicotine CS training (bottom graph), respectively. ${ }^{\wedge}$ denotes a significant main effect of $\mathrm{CP} 55,940$ training without an interaction. * denotes significant difference between nicotine and saline sessions. Panel c shows locomotor activity during $0.01 \mathrm{mg} / \mathrm{kg} \mathrm{CP} 55,940$ CS training. Panels d show locomotor activity per second for rats remaining on CP 55,940 (top graph) and for rats switched from CP 55,940 to nicotine CS training (bottom graph), respectively. * denotes significant difference between nicotine and saline sessions

each dose, there were main effects of Drug, Fs $\geq 15.65, p s$ $\leq .002$, but no main effect of Session or Drug $\times$ Session interaction.

CP 55940 feature positive training: $0.03 \mathrm{mg} / \mathrm{kg}$ group Similar to the $0.01 / 0.03 \mathrm{mg} / \mathrm{kg}$ group, when rats were trained with $0.03 \mathrm{mg} / \mathrm{kg}$ CP 55,940 from the outset a very weak discrimination developed (data not shown). There was a main effect of Drug, $F(1,295)=6.97, p<$ 0.05 , with the light CS evoking slightly higher initial elevation scores after CP 55,940 than vehicle administration. There was no effect of Session or Drug $\times$ Session interaction. Locomotor activity was slightly higher on CP 55,940 sessions than vehicle sessions, with an overall decrease in activity across sessions (data not shown).
These observations were supported by main effects of Drug, $F(1,5)=7.41, p<0.05$, and Session, $F(59,295)=$ 2.41, $p<0.001$, and a Drug $\times$ Session interaction, $F(59$, $295)=1.39, p<0.05$. However, after Bonferrroni's correction, none of the comparisons were significant.

\section{Discussion}

Rats readily acquired the Pavlovian drug discrimination when $0.2 \mathrm{mg} / \mathrm{kg}$ nicotine was paired with a water US. This finding extends previous research from our laboratory to a new US. Past research used food restriction and a sucrose US. The studies that used $0.2 \mathrm{mg} / \mathrm{kg}$ nicotine as the training dose yielded similar to slightly higher $\mathrm{ED}_{50} \mathrm{~s}$ [from 0.049 in Murray and Bevins (2007a) 

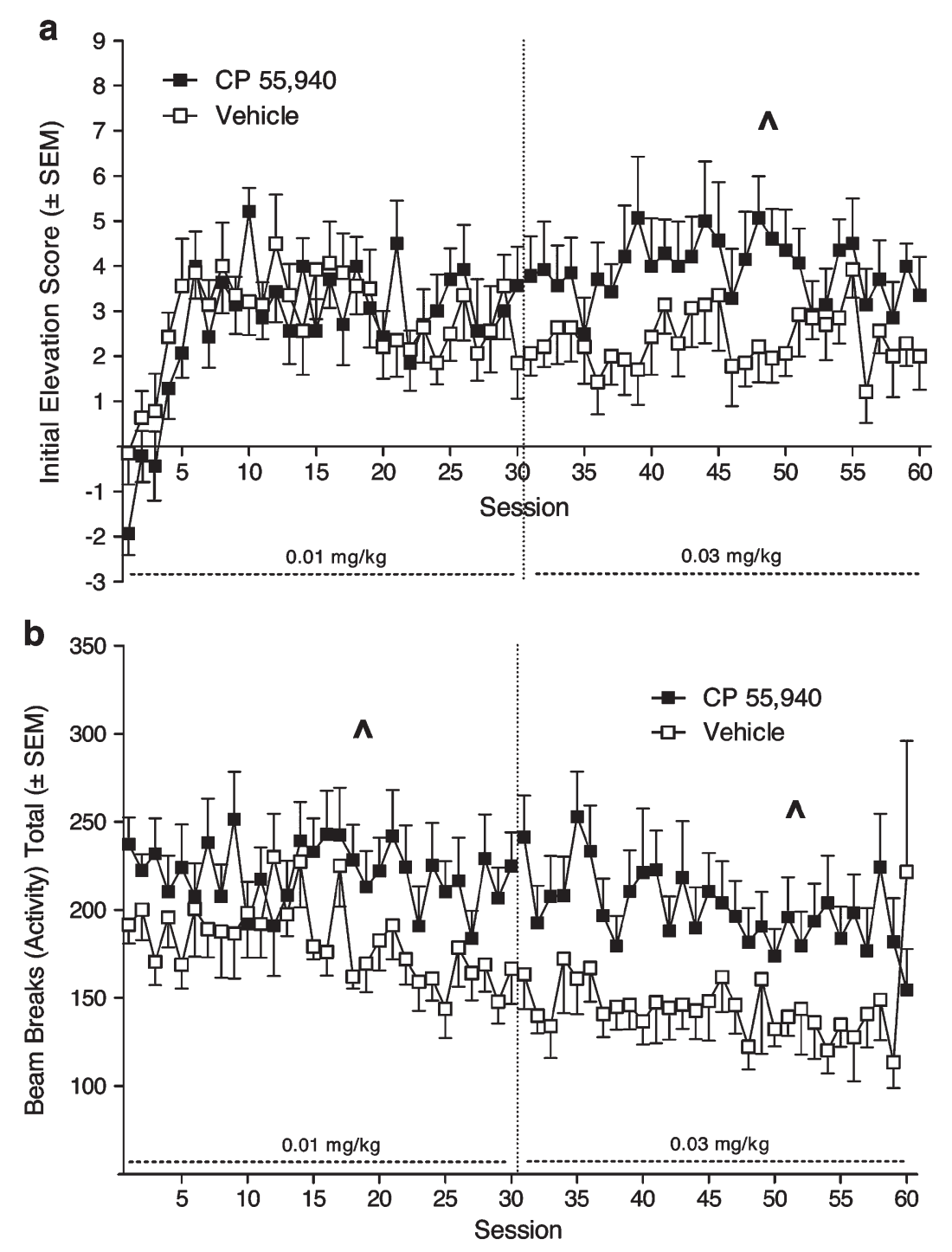

Figure 4. Panel a shows initial elevation scores for rats trained with $0.01 \mathrm{mg} / \mathrm{kg}$ then $0.03 \mathrm{mg} / \mathrm{kg}$ CP 55,940 as a positive drug feature. Panel $\mathbf{b}$ shows locomotor activity during training. For both panels, $\wedge$ denotes a significant main effect of Drug without an interaction

to $0.075 \mathrm{mg} / \mathrm{kg}$ in Reichel et al. (2007a)] than the 0.052 $\mathrm{mg} / \mathrm{kg}$ nicotine found in the present study. We also found a role for endocannabinoid activation in the expression of the interoceptive CS effects of nicotine. Rimonabant partially blocked the CS effects of nicotine without affecting locomotor activity at $1 \mathrm{mg} / \mathrm{kg}$. At $3 \mathrm{mg} / \mathrm{kg}$, there was a concurrent reduction in locomotion and dipper entries, a finding that is potentially consistent with a response competition account of reduced locomotion after administration of rimonabant (Tallett et al. 2007). In that study, 1.5 and $3 \mathrm{mg} / \mathrm{kg}$ rimonabant reduced locomotion while enhancing grooming and scratching behaviors. Future research involving video recording of behavior during test sessions would be needed to assess this speculation. Our finding with the 1 $\mathrm{mg} / \mathrm{kg}$ dose of rimonabant complements the well-documented role of endocannabinoids in the US or reinforcing effects of nicotine (e.g., Castañé et al. 2002; Kodas et al. 2007). However, the results are in contrast to the operant drug discrimination literature. In those studies, rimonabant at a range of 0.3 to $3 \mathrm{mg} / \mathrm{kg}$ (Cohen et al. 2002; Le Foll and Goldberg 2004) or even 5 to $10 \mathrm{mg} /$ $\mathrm{kg}$ (Zaniewska et al. 2006) did not affect the distribution of nicotine-appropriate responding. In those studies, the effect of rimonabant on rates of responding was mixed, with two of the three studies showing no change in response rate (Le Foll and Goldberg 2004; Zaniewska et al. 2006). Furthermore, in the current study, $0.01 \mathrm{mg} / \mathrm{kg} \mathrm{CP}$ 55,940 partially substituted for the training dose and enhanced responding to a low dose of nicotine. However, in the operant-conditioning study by Zaniewska et al. (2006), pretreatment with a higher dose of CP 55,940 (0.1 $\mathrm{mg} / \mathrm{kg}$ ) had no effect on nicotine discrimination performance or rate of responding.

There are several possible reasons for the differences between the present studies and those just described. 
For instance, the dose of nicotine used as an $\mathrm{S}^{\mathrm{D}}$ was 0.4 $\mathrm{mg} / \mathrm{kg}$; the present study used $0.2 \mathrm{mg} / \mathrm{kg}$ nicotine as the CS training dose. The $0.4 \mathrm{mg} / \mathrm{kg}$ dose during the nicotine generalization test did not evoke a CR (i.e., dipper entries were at saline levels), a finding consistent with the suggestion that the interoceptive stimulus effects of $0.2 \mathrm{mg} / \mathrm{kg}$ differ from $0.4 \mathrm{mg} / \mathrm{kg}$. In Murray and Bevins (2007a), $0.4 \mathrm{mg} / \mathrm{kg}$ also did not generalize to $0.2 \mathrm{mg} / \mathrm{kg}$ nicotine. Additionally, extinction of the $0.4 \mathrm{mg} / \mathrm{kg}$ nicotine CS proceeded more slowly than the $0.2 \mathrm{mg} / \mathrm{kg}$ CS (Murray and Bevins 2007b). Finally, in the operant drug discrimination task, rats trained on $0.4 \mathrm{mg} / \mathrm{kg}$ learned the discrimination faster than rats trained on $0.2 \mathrm{mg} /$ $\mathrm{kg}$ (cf. Chance et al. 1977). Another reason may be that previous research with CP 55,940 or rimonabant and the stimulus effects of nicotine used the two-lever operant-discrimination task with separate schedules of reinforcement in force depending on drug state. The present research used a Pavlovian discriminated goal-tracking task in which the reinforcer was made available independent of responding. If this distinction eventuates to be important, then present results are the second neuropharmacological distinction found between the stimulus effects of nicotine as a CS versus an $S^{\mathrm{D}}$. The first one was described by Murray and Bevins (2007a). In that study, the N-methyl-D-aspartate receptor channel blocker MK801 attenuated conditioned responding evoked by a nicotine CS. In contrast, nicotine-appropriate operant responding was unchanged after MK-801 pretreatment in Zakharova et al. (2005) and Kim and Brioni (1995).

Because the interoceptive effects of CP 55,940 enhanced conditioned responding to the nicotine CS, we hypothesized that this cannabinoid agonist would also function as a CS. However, after twice the training as that for nicotine, there was still no suggestion that conditioned responding was coming under control of the CP 55,940 drug state. The subset of rats subsequently switched to nicotine quickly acquired the Pavlovian discrimination. Thus, CP 55,940 shares some stimulus effects with nicotine as measured by partial substitution for the nicotine CS and its enhancement of conditioned responding to a low non-training dose of nicotine. The stimulus effects of $0.01 \mathrm{mg} / \mathrm{kg} \mathrm{CP} \mathrm{55,940} \mathrm{itself,} \mathrm{how-}$ ever, were not sufficient to function as a CS for access to water. Notably, switching to nicotine training revealed the locomotor-inhibiting effects of early nicotine exposure and suggests no cross-tolerance developed with CP 55,940 exposure.

Research from our laboratory has shown that thus far, drugs other than nicotine (i.e., amphetamine, caffeine, and chlordiazepoxide) do not readily come to control a CR when trained as a CS (Murray et al. 2007; Palmatier and Bevins 2007). In contrast, up to this point, every drug state tested by us has functioned as a positive drug feature occasioning when a discrete CS will be reinforced. That list includes amphetamine, bupro- pion, caffeine, chlordiazepoxide, cocaine, methamphetamine, and nicotine (Murray et al. 2007; Palmatier and Bevins 2007; Reichel et al. 2007b; Wilkinson et al. 2008). Further, midazolam was an effective positive drug feature disambiguating a context CS-shock US pairings in rats (Maes et al. 1996). Midazolam, as well as amphetamine, were effective when trained as positive features for light CS-food pellet pairings in rats (Maes and Vossen 1997). Troisi and Akins (2004) found that a cocaine-positive feature facilitated conditioned approach behavior to a wood block CS paired with copulatory opportunity in male quail. Finally, drugs such as morphine and fentanyl serve as positive drug features that signal when a saccharin solution will be paired illness (Jaeger and Mucha 1990; Skinner et al. 1998). Although not an exhaustive list, clearly there is evidence that drug states function as positive features. As such, we trained CP 55,940 as a positive drug feature. Even though there was clear evidence of biological activity of the CP 55,940 in the present study (e.g., altering activity, substituting for nicotine, etc.), the drug did not reliably modulate (facilitate) conditioned responding to the light. This is the first example of a drug with demonstrable $S^{\mathrm{D}}$ effects (cf. De Vry and Jentzsch 2003; Mauler et al. 2002) not functioning as a positive feature in our discriminated goaltracking task.

One of the compounds that functioned as a positive feature in earlier research was chlordiazepoxide (e.g., Palmatier and Bevins 2008). The authors found that CR topography changed when using a white noise rather than a light CS. Rats were holding their heads in the dipper receptacle longer rather than more often. There is a detailed literature showing that conditioned response form can vary as a function of stimulus modality (e.g., Bevins and Ayres 1991; Farwell and Ayres 1979). To determine whether the more-maintained head-poke CR developed to the light CS on CP 55,940 sessions, we assessed the duration (rather than frequency) of dipper entries. The pattern of results was no different than that for the frequency of entries described in the "Results" section. Thus, CP 55,940 did not appear to alter the response topography to the light CS in these studies.

Another potential explanation of the findings involves the effects of exogenous cannabinoids on memory function (for reviews, see Davies et al. 2002; Ranganathan and D'Souza 2006). For example, the CB partial agonist, $\Delta^{9}$-tetrahydrocannabinol (THC; French 1997; Petitet et al. 1998), has been shown to induce performance deficits in the radial arm maze (Lichtman and Martin 1996) and the Morris water maze (Da Silva and Takahashi 2002) in rodents. Administration of rimonabant blocked the deficits in both tasks, indicating $\mathrm{CB}_{1}$ receptor specificity of memory for the task. Additionally, intrahippocampal infusions of CP 55,940 impaired performance in the radial arm maze (Lichtman et al. 1995), whereas infusions of rimonabant enhanced water-maze performance (Rob- 
inson et al. 2008). Perhaps the impairment of acquisition in the present studies is due to the memory-deficit effects of cannabinoid activation. This seems unlikely given our findings that CP 55,940 increased nicotine-appropriate responding, whereas rimonabant decreased nicotine-appropriate responding. This pattern is the opposite of what would be expected had memory function been the primary factor involved in the cannabinoid modification of the nicotine CS. In addition, CP 55,940 effectively served as a $S^{\mathrm{D}}$ indicating that it can acquire control over behavior (e.g., Wiley et al. 1995a). Overall, we are led to the conclusion that at the dose used, and within the training conditions of the present research, CP 55,940 is not effective as a Pavlovian stimulus (i.e., a CS or positive feature).

Of course, acceptance of this conclusion without the above caveat would be premature given that there are numerous experimental parameters that could be manipulated. One example is the training dose. We started with $0.01 \mathrm{mg} / \mathrm{kg}$ CP 55,940 because this dose significantly modified conditioned responding to the nicotine CS. The $0.01 \mathrm{mg} / \mathrm{kg} \mathrm{CP} \mathrm{55,940} \mathrm{is} \mathrm{a} \mathrm{relatively} \mathrm{low}$ dose in the cannabinoid literature (cf. De Vry and Jentzsch 2003; Wiley et al. 1995a); a higher dose may be a more effective drug feature. Indeed, a weak discrimination developed when the training dose was increased to $0.03 \mathrm{mg} / \mathrm{kg}$ CP 55,940. However, when the higher dose of CP 55,940 served as the drug feature at the start of training (i.e., $0.03 \mathrm{mg} / \mathrm{kg}$ group) discrimination performance was still weak and inconsistent. Although operant drug discrimination research has shown that 0.03 $\mathrm{mg} / \mathrm{kg} \mathrm{CP} \mathrm{55,940} \mathrm{was} \mathrm{sufficient} \mathrm{to} \mathrm{function} \mathrm{as} \mathrm{an} \mathrm{S}^{\mathrm{D}}$ (De Vry and Jentzsch 2003; Mauler et al. 2002), perhaps an even higher dose was needed in the Pavlovian positive feature task. Another potential parametric change is to increase the length of training. We trained the CP 55,940 CS for twice the number of sessions as the nicotine CS, and the CP 55,940 positive features were trained for more than twice that of the CP 55,940 CS. Further, De Vry and Jentzsch (2003), as well as Mauler et al. (2002), showed that rats acquired the $0.03 \mathrm{mg} / \mathrm{kg} \mathrm{CP} \mathrm{55,940}$ operant discrimination in a median of 38 training sessions (cf. to the 120 training sessions in the present $\mathrm{CP}$ 55,940 experiments). It seems unlikely that more training would have conditioned a stronger discrimination in the present studies.

Overall, the results of the present research indicate a mediating role of endocannabinoids in the nicotine CS. However, the cannabinoid agonist, CP 55,940, does not have Pavlovian stimulus effects using the current parameters. Because rimonabant does not alter schedulecontrolled responding by a nicotine $\mathrm{S}^{\mathrm{D}}$ (Cohen et al. 2002; Le Foll and Goldberg 2004; Zaniewska et al. 2006), and because CP 55,940 functions as an effective operant $\mathrm{S}^{\mathrm{D}}$ at the doses used here (De Vry and Jentzsch 2003; Mauler et al. 2002; Wiley et al. 1995a, b), the current re- search suggests a potential dissociation between the mechanisms mediating operant and Pavlovian stimulus effects of nicotinic and cannabinoidergic compounds that warrant further investigation (cf. Murray and Bevins 2007a).

Acknowledgments The authors would like to thank Veronica C. Barra and Kimberly D. Horky for their dedicated assistance with the animals and to thank Dr. Calvin P. Garbin for his statistical assistance. We gratefully recognize the National Institute on Drug Abuse Drug Supply Program for providing the rimonabant and CP 55,940. The research and R. A. Bevins were partially supported by United States Public Health Service Grant DA018114. J. E. Murray was supported by DA025399 during the preparation of this manuscript. N. R. Wells was partially supported by UNL Undergraduate Creative Activities and Research Experiences. These organizations had no role in the study design, data collection, analysis, or the interpretation, the writing of the manuscript, or the decision to submit the paper for publication. MED-PC programs described in this article are available upon request.

\section{References}

Beardsley PM, Thomas BF (2005) Current evidence supporting a role of cannabinoid $\mathrm{CB}_{1}$ receptor (CB1R) antagonists as potential pharmacotherapies for drug abuse disorders. Behav Pharmacol 16:275-296

Besheer J, Palmatier MI, Metschke DM, Bevins RA (2004) Nicotine as a signal for the presence or absence of sucrose reward: a Pavlovian drug appetitive conditioning preparation in rats. Psychopharmacology (Berl.) 172:108-117

Bevins RA, Ayres JJB (1991) Two issues in Pavlovian fear conditioning: selective fear of bright vs. dark, and CS determinants of CR form. Behav Process 24:211-218

Castañé A, Valjent E, Ledent C, Parmentier M, Maldonado R, Valverde O (2002) Lack of CB1 cannabinoid receptors modifies nicotine behavioural responses, but not nicotine abstinence. Neuropharmacology 43:857-867

Castañé A, Berrendero F, Maldonado R (2005) The role of the cannabinoid system in nicotine addiction. Pharmacol Biochem Behav 81:381-386

Chance WT, Murfin D, Krynock GM, Rosencrans JA (1977) A description of the nicotine stimulus and tests of its generalization to amphetamine. Psychopharmacology (Berl.) 55:19-26

Cohen C, Perrault G, Voltz C, Steinberg R, Soubrié P (2002) SR141716, a central cannabinoid $\left(\mathrm{CB}_{1}\right)$ receptor antagonist, blocks the motivational and dopamine-releasing effects of nicotine in rats. Behav Pharmacol 13:451-463

Cohen C, Perrault G, Griebel G, Soubrie P (2004) Nicotineassociated cues maintain nicotine-seeking behavior in rats several weeks after nicotine withdrawal: reversal by the cannabinoid (CB1) receptor antagonist, rimonabant (SR141716). Neuropsychopharmacology 30:145-155

Da Silva GE, Takahashi RN (2002) SR 141716A prevents $\Delta^{9}-$ tetrahydrocannabinol-induced spatial learning deficit in a Morris-type water maze in mice. Prog Neuropsychopharmacol Biol Psychiatry 26:321-325 
Davies SN, Pertwee RG, Riedel G (2002) Functions of cannabinoid receptors in the hippocampus. Neuropharmacology 42:993-1007

De Vries TJ, De Vries W, Janssen MC, Schoffelmeer AN (2005) Suppression of conditioned nicotine and sucrose seeking by the cannabinoid-1 receptor antagonist SR141716A. Behav Brain Res 161:164-168

De Vry J, Jentzsch KR (2003) Intrinsic activity estimation of cannabinoid CB1 receptor ligands in a drug discrimination paradigm. Behav Pharmacol 14:471-476

Farwell BJ, Ayres JJB (1979) Stimulus-reinforcer and responsereinforcer relations in the control of conditioned appetitive headpoking ("goal-tracking") in rats. Learn Motiv 10:295-312

Forget B, Hamon M, Thiébot M-H (2005) Cannabinoid $\mathrm{CB}_{1}$ receptors are involved in motivational effects of nicotine in rats. Psychopharmacology (Berl.) 181:722-734

French ED (1997) $\Delta^{9}$-Tetrahydrocannabinol excites rat VTA dopamine neurons through activation of cannabinoid CB1 but not opioid receptors. Neurosci Lett 226:159-162

Glick SD, Milloy S (1972) Increased and decreased eating following THC administration. Psychon Sci 29:6

Jaeger TV, Mucha RF (1990) A taste aversion model of drug discrimination learning: training drug and condition influence rate of learning, sensitivity and drug specificity. Psychopharmacology 100:145-150

Kim DJB, Brioni JD (1995) Modulation of the discriminative stimulus properties of $(-)$-nicotine by diazepam and ethanol. Drug Dev Res 34:47-54

Kodas E, Cohen C, Louis C, Griebel G (2007) Cortico-limbic circuitry for conditioned nicotine-seeking behavior in rats involves endocannabinoid signaling. Psychopharmacology (Berl.) 194:161-171

Lamota L, Bermudez-Silva FJ, Marco E-M, Llorente R, Gallego A, Rodríguez de Fonseca F, Viveros M-P (2008) Effects of adolescent nicotine and SR 147778 (Surinabant) administration on food intake, somatic growth and metabolic parameters in rats. Neuropharmacology 54:194-205

Le Foll B, Goldberg SR (2004) Rimonabant, a $\mathrm{CB}_{1}$ antagonist, blocks nicotine-conditioned place preferences. NeuroReport 15:2139-2143

Lichtman AH, Martin BR (1996) Delta-9-tetrahydrocannabinol impairs spatial memory through a cannabinoid receptor mechanism. Psychopharmacology (Berl.) 126:125-131

Lichtman AH, Dimen KR, Martin BR (1995) Systemic or intrahippocampal cannabinoid administration impairs spatial memory in rats. Psychopharmacology (Berl.) 119:282-290

Little PJ, Compton DR, Johnson MR, Melvin LS, Martin BR (1988) Pharmacology and stereoselectivity of structurally novel cannabinoids in mice. J Pharmacol Exp Ther 247:1046-1051

Maes JHR, Vossen JMH (1997) Conditional control by midazolam and amphetamine in a rapid appetitive discrimination procedure. Eur J Pharmacol 319:5-11

Maes JHR, Van Rijn CM, Vossen JMH (1996) Drug states as modulators of conditioned immobility in a latent discrimination procedure. Eur J Pharmacol 309:131-140

Mauler F, Mittendorf J, Horváth E, De Vry J (2002) Characterization of the diarylether sulfonylester (-)-(R)-3-(2-hydroxymethylindanyl-4-oxy) phenyl-4, 4, 4-trifluoro-1-sulfonate (BAY 38-7271) as a potent cannabinoid receptor agonist with neuroprotective properties. J Pharmacol Exp Ther 302:359-368

Murray JE, Bevins RA (2007a) Behavioral and neuropharmacological characterization of nicotine as a conditional stimulus. Eur J Pharmacol 561:91-104

Murray JE, Bevins RA (2007b) The conditional stimulus effects of nicotine vary as a function of training dose. Behav Pharmacol 18:707-716

Murray JE, Li C, Palmatier MI, Bevins RA (2007) The interoceptive Pavlovian stimulus effects of caffeine. Pharmacol Biochem Behav 86:838-846

National Research Council (2003) Guidelines for the care and use of mammals in neuroscience and behavioral research. National Academy Press, Washington, DC

Palmatier MI, Bevins RA (2007) Facilitation by drug states does not depend on acquired excitatory strength. Behav Brain Res 176:292-301

Palmatier MI, Bevins RA (2008) Occasion setting by drug states: functional equivalence following similar training history. Behav Brain Res 195:260-270

Pan X, Ikeda SR, Lewis DL (1998) SR 141716A acts as an inverse agonist to increase neuronal voltage-dependent $\mathrm{Ca} 2+$ currents by reversal of tonic CB1 cannabinoid receptor activity. Mol Pharmacol 54:1064-1072

Petitet F, Jeantaud B, Reibaud M, Imperato A, Dubroeucq MC (1998) Complex pharmacology of natural cannabinoids: evidence for partial agonist activity of delta-9-tetrahydrocannabinol and antagonist activity of cannabidiol on rat brain cannabinoid receptors. Life Sci 63:PL1-PL6

Reichel CM, Bevins RA (2008) Competition between the conditioned rewarding effects of cocaine and novelty. Behav Neurosci 122:140-150

Reichel CM, Linkugel JD, Bevins RA (2007a) Nicotine as a conditioned stimulus: impact of attention-deficit/hyperactivity disorder medications. Exp Clin Psychopharmacol 15:501-509

Reichel CM, Wilkinson JL, Bevins RA (2007b) Methamphetamine functions as a positive and negative drug feature in a Pavlovian appetitive discrimination task. Behav Pharmacol 18:755-765

Rinaldi-Carmona M, Barth F, Héaulme M, Shire D, Calandra B, Congy C, Martinez S, Maruani J, Néliat G, Caput D, Ferrara P, Soubrié P, Brelière JC, Le Fur G (1994) SR 141716A, a potent and selective antagonist of the brain cannabinoid receptor. FEBS Lett 350:240-244

Rinaldi-Carmona M, Barth F, Cogny C, Martinez S, Oustric D, Pério A, Poncelet M, Maruani J, Arnone M, Finance O, Soubrié P, Le Fur G (2004) SR147778 [5-(4-Bromophenyl)-1-(2, 4-dichlorophenyl)-4-ethyl- $\mathrm{N}$-(1-piperidinyl)-1H-pyrazole3-carboxamide], a new potent and selective antagonist of the CB1 cannabinoid receptor: biochemical and pharmacological characterization. J Pharmacol Exp Ther 310:905-914

Ranganathan M, D'Souza DC (2006) The acute effects of cannabinoids on memory in humans: a review. Psychopharmacology (Berl.) 188:425-444

Robinson L, McKillop-Smith S, Ross NL, Pertwee RG, Hampson RE, Platt B, Riedel G (2008) Hippocampal endocannabinoids inhibit spatial learning and limit spatial memory in rats. Psychopharmacology (Berl.) 198:551-563

Skinner DM, Goddard MJ, Holland PC (1998) What can nontraditional features tell us about conditioning and occa- 
sion setting? In: Schmajuk NA, Holland PC (eds) Occasion setting: Associative learning and cognition in animals. American Psychological Association, Washington, DC, pp 113-144

Tallett AJ, Blundell JE, Rodgers RJ (2007) Grooming, scratching and feeding: role of response competition in acute anorectic response to rimonabant in male rats. Psychopharmacology (Berl.) 195:27-39

Thomas BF, Gilliam AF, Burch DF, Roche MJ, Seltzman HH (1998) Comparative receptor binding analyses of cannabinoid agonists and antagonists. J Pharmacol Exp Ther 285:285-292

Troisi JR, Akins C (2004) The discriminative stimulus effects of cocaine in a Pavlovian sexual approach paradigm in male Japanese quail. Exp Clin Psychopharmacol 12:237-242

Wiley JL, Barrett RL, Lowe J, Balster RL, Martin BR (1995a) Discriminative stimulus effects of CP 55, 940 and structurally dissimilar cannabinoids in rats. Neuropharmacology 34:669-676

Wiley J, Balster R, Martin B (1995b) Discriminative stimulus effects of anandamide in rats. Eur J Pharmacol 276:49-54
Wilkinson JL, Li C, Bevins RA (2008) Pavlovian drug discrimination with bupropion as a feature positive occasion setter: Substitution by methamphetamine and nicotine, but not cocaine. Addict Biol 14:165-173

Xie S, Furjanic MA, Ferrara JJ, McAndrew NR, Ardino EL, Ngondara A, Bernstein Y, Thomas KJ, Kim E, Walker JM, Nagar S, Ward SJ, Raffa RB (2007) The endocannabinoid system and rimonabant: a new drug with a novel mechanism of action involving cannabinoid CB1 receptor antagonism - or inverse agonism - as potential obesity treatment and other therapeutic use. J Clin Pharm Ther 32:209-231

Zakharova ES, Danysz W, Bespalov AY (2005) Drug discrimination analysis of NMDA receptor channel blockers as nicotinic receptor antagonists in rats. Psychopharmacology (Berl.) 179:128-135

Zaniewska M, McCreary AC, Przegaliński E, Filip M (2006) Evaluation of the role of nicotinic acetylcholine receptor subtypes and cannabinoid system in the discriminative stimulus effects of nicotine in rats. Eur J Pharmacol 540:96-106 